\title{
Artificial Intelligence in Rehabilitation Targeting the Participation of Children and Youth With Disabilities: Scoping Review
}

Vera C Kaelin ${ }^{1,2}$, MSc; Mina Valizadeh ${ }^{3,4}$, BSc; Zurisadai Salgado ${ }^{2,5}$, BSc; Natalie Parde ${ }^{3,4^{*}}$, PhD; Mary A Khetani ${ }^{1,2,5,6^{*}}$, $\mathrm{ScD}$

${ }_{1}^{1}$ Rehabilitation Sciences, College of Applied Health Sciences, University of Illinois at Chicago, Chicago, IL, United States

${ }^{2}$ Children's Participation in Environment Research Lab, University of Illinois at Chicago, Chicago, IL, United States

${ }^{3}$ Computer Science, College of Engineering, University of Illinois at Chicago, Chicago, IL, United States

${ }^{4}$ Natural Language Processing Laboratory, University of Illinois at Chicago, Chicago, IL, United States

${ }^{5}$ Occupational Therapy, College of Applied Health Sciences, University of Illinois at Chicago, Chicago, IL, United States

${ }^{6}$ CanChild Centre for Childhood Disability Research, McMaster University, Hamilton, ON, Canada

* these authors contributed equally

\section{Corresponding Author:}

Mary A Khetani, ScD

Occupational Therapy

College of Applied Health Sciences

University of Illinois at Chicago

1919 West Taylor Street, Room 316A

Chicago, IL, 60612-7250

United States

Phone: 13129960942

Email: mkhetani@uic.edu

\section{Abstract}

Background: In the last decade, there has been a rapid increase in research on the use of artificial intelligence (AI) to improve child and youth participation in daily life activities, which is a key rehabilitation outcome. However, existing reviews place variable focus on participation, are narrow in scope, and are restricted to select diagnoses, hindering interpretability regarding the existing scope of AI applications that target the participation of children and youth in a pediatric rehabilitation setting.

Objective: The aim of this scoping review is to examine how AI is integrated into pediatric rehabilitation interventions targeting the participation of children and youth with disabilities or other diagnosed health conditions in valued activities.

Methods: We conducted a comprehensive literature search using established Applied Health Sciences and Computer Science databases. Two independent researchers screened and selected the studies based on a systematic procedure. Inclusion criteria were as follows: participation was an explicit study aim or outcome or the targeted focus of the AI application; AI was applied as part of the provided and tested intervention; children or youth with a disability or other diagnosed health conditions were the focus of either the study or AI application or both; and the study was published in English. Data were mapped according to the types of AI, the mode of delivery, the type of personalization, and whether the intervention addressed individual goal-setting.

Results: The literature search identified 3029 documents, of which 94 met the inclusion criteria. Most of the included studies used multiple applications of AI with the highest prevalence of robotics (72/94, 77\%) and human-machine interaction (51/94, $54 \%)$. Regarding mode of delivery, most of the included studies described an intervention delivered in-person (84/94, 89\%), and only $11 \%$ (10/94) were delivered remotely. Most interventions were tailored to groups of individuals (93/94, 99\%). Only 1\% (1/94) of interventions was tailored to patients' individually reported participation needs, and only one intervention (1/94, $1 \%)$ described individual goal-setting as part of their therapy process or intervention planning.

Conclusions: There is an increasing amount of research on interventions using AI to target the participation of children and youth with disabilities or other diagnosed health conditions, supporting the potential of using AI in pediatric rehabilitation. On the basis of our results, 3 major gaps for further research and development were identified: a lack of remotely delivered participation-focused interventions using AI; a lack of individual goal-setting integrated in interventions; and a lack of interventions tailored to individually reported participation needs of children, youth, or families. 
(J Med Internet Res 2021;23(11):e25745) doi: 10.2196/25745

\section{KEYWORDS}

health care; pediatric rehabilitation; technology; young persons; robotics; human-machine interaction; personalization; customization; goal-setting; natural language processing; machine learning

\section{Introduction}

\section{Background}

Technology-based interventions are of increased importance in pediatric rehabilitation and can be useful to rehabilitation practitioners when delivering family-centered and function-focused interventions to service-eligible children, youth, and families [1]. In addition, technology-based rehabilitation tools can be useful to organizations that have electronic data capture systems to monitor trends in rehabilitation service use and outcomes for quality improvement $[2,3]$. For both individuals and organizations, the COVID-19 pandemic has heightened the demand for technological solutions to remotely deliver and monitor rehabilitation services [4].

One way to provide technology-based pediatric rehabilitation is by applying artificial intelligence (AI), which is a priority of the National Institutes of Health, as reflected in their Rehabilitation Research Plan [5,6]. According to Russell and Norvig [7], AI is concerned with designing and building systems that think like humans, act like humans, think rationally, and act rationally. It encompasses different subfields such as natural language processing (NLP), robotics, or human augmentics [7]. The application of AI in pediatric rehabilitation has the potential to simplify steps in the therapeutic process and possibly decrease provider and patient burden as well as afford providers to customize their rehabilitation services.

Rehabilitation includes a broad range of highly variable interventions that are challenging to define owing to their complexity [8-10]. One important way to classify rehabilitation intervention is through its targeted outcome [9]. In the last decade, there has been a rapid increase in research on the use of AI to improve key pediatric rehabilitation outcomes, including body functions, activity performance, and the full participation of children and youth with disabilities in valued activities [11-13]. For children and youth, participation in home, school, and community activities has been defined by the World Health Organization as "involvement in life situations" [14] and was further conceptualized by Imms et al [15] as attendance and involvement in activities, which is related to but distinct from their activity competencies, environment or context, and their preferences or sense of self [15]. Given the unmet participation need among children or youth with disabilities and other diagnosed health conditions, beginning in early childhood and across settings [16-19], there is a growing number of participation-focused intervention studies [20], including interventions that integrate $\mathrm{AI}$ to target the participation of young persons receiving pediatric rehabilitation.

A recent systematic literature review on the effect of participation-focused pediatric rehabilitation identified 2257 records through a database search, indicating the high relevance of participation as an outcome in pediatric rehabilitation interventions [20]. However, this review does not focus on AI use. Literature reviews focusing on AI indicate that the use of $\mathrm{AI}$ in the form of information and communication technology or robots may improve children's engagement in play, stimulate school performance [13], and promote social interactions $[11,12]$. However, these reviews place variable focus on participation [11-13], are narrow in scope (eg, focus on participation in play only) [13], and are restricted to select diagnoses (eg, physical disability) [13]. These limitations hinder our understanding of the existing scope of AI applications in pediatric rehabilitation that target participation in daily life activities.

\section{Objectives}

To better understand the current scope of AI applications within pediatric rehabilitation and to identify gaps for future research, there is a critical need to summarize existing evidence on the use of AI across interventions targeting child and youth participation in activities. The purpose of this scoping review is to examine how AI is integrated into pediatric rehabilitation interventions targeting the participation of children and youth with disabilities or other diagnosed health conditions in valued activities.

\section{Our paper's contributions are as follows:}

1. An overview of the scope of literature focusing on AI targeting participation as a primary pediatric rehabilitation outcome and top priority from the perspective of families.

2. A summary of the types of AI and personalization used in the interventions over a time span of more than 20 years.

3. Identification of research gaps based on the found and summarized literature with a focus on AI targeting the participation of children and youth with disabilities or other diagnosed health conditions.

\section{Methods}

\section{Design}

Scoping reviews are commonly used to provide an overview of existing evidence in a certain field and identify gaps for future research $[21,22]$. The increasing number of publications on the use of AI in participation-focused pediatric rehabilitation indicates an emerging field for the advancement of rehabilitation research and therefore justifies the need to conduct this scoping review [21]. The protocol for this scoping review was registered in the Open Science Framework [23].

\section{Search Strategy}

The first author of this review (VCK) conducted a systematic literature search in well-established databases in the fields of Applied Health Sciences and Computer Science (PubMed, PsycINFO, ERIC, CINAHL, IEEE Xplore, and ACM Digital Library) for documents published before February 2021. No 
other publication data limit or search limitations were applied to the search. We solicited support from a health sciences librarian to develop subject headings for each database with available thesaurus (ie, PubMed, PsycINFO, ERIC, and CINAHL) and keywords for artificial intelligence, participation, health care, disability, and young persons (Textbox 1) [24,25]. These were applied using truncations and Boolean terms, resulting in 2496 documents (Figure 1). The full search strategy is presented in Multimedia Appendix 1. After consultation with an AI expert (NP), additional searches were performed in ACL Anthology and AAAI Digital Library, using the same keywords from the database searches. This led to an additional 533 documents.

Textbox 1. Search strategy.

\section{Main search term and additional search terms for abstract and title search}

- $\quad$ artificial intelligence

- affective computing, algorithms, chatbot, cognitive computing, computer vision, constraint optimization, constraint satisfaction, data mining, data processing, deep learning, expert systems, feature extraction, fuzzy logic, game theory, human computation, image analysis, inductive logic programming, knowbot*, knowledge bases, knowledge-based agent, knowledge engineering, knowledge representation, machine learning, natural language processing, neural networks, pattern recognition, predictive model, reinforcement learning, robot*, semantic networks, semi-supervised learning, supervised learning, text analysis, unsupervised learning, virtual agent, virtual reality

- participation

- $\quad$ attendance, engag*, inclus*, involvement

- $\quad$ health care

- $\quad$ health care, healthcare, rehabilitation, therap*

- disability

- $\quad$ disab*, handicap*, impair*, special needs, special need

- young persons

- $\quad$ adolesc*, caregiv*, child*, family, families, infant*, paediatric*, parent*, pediatric*, student*, teen*, toddler*, young adult, young adults, youth*

Figure 1. Study selection process.

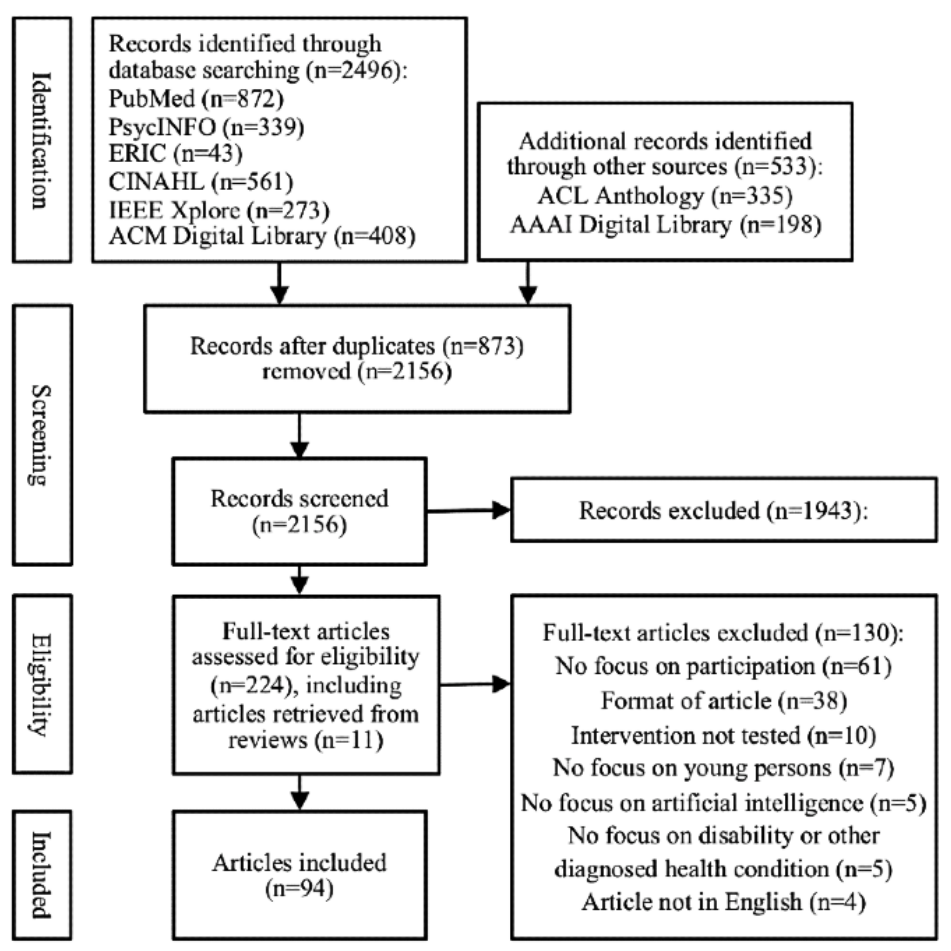




\section{Screening and Selection Process}

After removal of duplicates, 2 independent coders (VCK and MV) applied inclusion and exclusion criteria to the title and abstracts of the remaining documents. Documents indicating potential fit based on their abstract or title underwent full-text reading and were coded based on the same inclusion and exclusion criteria. First, 2 independent authors with expertise in participation-focused pediatric rehabilitation (VCK and ZS) coded the same documents until at least $80 \%$ agreement was reached [26]. Discrepancies and coding uncertainties were resolved through discussion. The remaining documents were screened separately (VCK and ZS), whereas $20 \%$ of randomly selected documents underwent double screening (ie, 10\%: VCK and $\mathrm{ZS} ; 10 \%$ including an external reviewer with expertise in participation-focused pediatric rehabilitation: VCK and Kyle A Truevillian) [26]. Doubts regarding document inclusion were discussed with a third reviewer (VCK, ZS, and Kyle A Truevillian). Second, documents indicating fit were further screened by an additional author (MV) with a specific focus on AI. Disagreements were resolved through discussion (VCK, ZS, MV, and Kyle A Truevillian) and with the help of additional key informants (MAK and NP).

Documents were included if (1) participation was an explicit study aim or outcome, or the targeted focus of the AI application; (2) AI was applied as part of the provided and tested intervention; (3) children or youth with a disability or other diagnosed health condition were the focus of either the study, AI application or both; and (4) the study was published in English. To ensure the inclusion of a broad scope of studies, no operational definition of participation was used when applying the selection criteria. Studies or AI interventions focused on participation; inclusion; engagement; playfulness; access to, or attendance in life situations, settings or activities; social interaction; or social engagement were considered participation and were therefore included in this review. Documents were excluded if (1) participation in daily activities was not the focus of the study (eg, focus was on skill development); (2) there was no use of AI for the described intervention (eg, the term algorithm was used in a noncomputer science way); (3) interventions using AI were not tested with either children, youth or both; (4) there was no focus on disability or other diagnosed health condition; (5) studies focused on adults (mean age $>24$ years [27]); (6) the study was published in languages other than English; or (7) documents were textbooks or textbook reviews, literature reviews, study protocols, conference or workshop programs, or only abstracts without additional information. To prevent missing relevant studies, each reference list of the excluded literature reviews was screened.

\section{Data Extraction and Analysis}

The data extraction template using Microsoft Excel was trialed with 5 studies by the first author and discussed with the author team to ensure the clarity and relevance of the included categories for data extraction [28]. Data were then extracted for all included studies based on the following categories: authors, year, title, sample size, child and youth age, child and youth race and ethnicity, family socioeconomic status, parental education, the types of $\mathrm{AI}$ applied in the intervention, the intervention's type of personalization, whether the primary method for intervention delivery was in-person or remote, and whether goal-setting was addressed as part of the intervention.

The mapping of included studies to one or multiple types of AI was guided by CSRankings [29] and the AAAI keywords taxonomy [30], 2 commonly used ranking systems and taxonomies for AI. The types of AI in this study include robotics, NLP, human computation and crowdsourcing, computer vision, knowledge representation and reasoning, machine learning (ML), human-machine interaction (HMI), cognitive modeling, constraint satisfaction and optimization, game theory, planning and routing and scheduling, and visualization and virtual reality (VR) [7]. As robotic devices are increasingly used in rehabilitation [31], studies that used robotics were further classified according to whether they focused on robot mechanics or on the system of use.

A framework developed by Fan et al [32] guided the mapping of the intervention's type of personalization according to 2 dimensions (ie, categorical vs individuated personalization; implicit vs explicit personalization). Categorical personalization targets a category of individuals, such as a diagnostic group or single-child families [32]. For this review, these were, for example, devices that are designed to include features that meet the common needs of children with autism spectrum disorder (ASD). Individuated personalization targets specific individuals [32], in the case of this review, individually perceived and reported participation needs. Implicit personalization is system-initiated, meaning it is automatically done by the system, whereas explicit personalization is user-initiated, meaning users manually guide the system on the preferred adaptation [32].

Interventions were mapped as in-person when the intervention was delivered face-to-face with a researcher or rehabilitation professional. Interventions were considered as remotely delivered when they were conducted in the child's natural environment and without a researcher or rehabilitation professional.

Mapping of included studies with regard to whether goal-setting was addressed as part of the described rehabilitation services was guided by the goal-setting and action-planning practice framework for rehabilitation settings [33]. Studies were mapped to address goal-setting if the described rehabilitation services included goal negotiation (ie, where the patient is at and where the patient would like to get to) or goal-setting (ie, what the patient would like to achieve) [33].

Charted data were summarized using descriptive statistics (ie, frequency counts and percentages) to provide an overview of the available evidence on how AI is used to support participation among children and youth with disabilities or other diagnosed health conditions.

\section{Results}

\section{Overview of Found and Included Research}

The literature search revealed 3029 documents with 873 duplicates (ie, documents appeared multiple times), resulting in 2156 documents entering the 2 -fold screening process to 
assess their eligibility based on the inclusion and exclusion criteria (Figure 1). The first screening phase included titles and abstracts and led to 213 included and 1943 excluded documents, as well as 11 additional studies found when screening the reference list of excluded literature reviews. The Cohen $\kappa$ for interrater agreement was 0.67 , indicating a substantial agreement [34]. This estimate did not include the numerous conference programs $(n=450)$ found through AAAI Digital Library and ACL Anthology, for which determining exclusion was trivial, resulting in a more conservative Cohen $\kappa$ value.

The second screening phase included a full-text review of the 224 included documents from the first screening phase, resulting in 94 included studies for this scoping review. Of the 130 excluded documents, 61 (46.9\%) lacked focus on participation, $38(29.2 \%)$ were excluded because of their format (ie, textbook or textbook review, study protocol, literature review, or only abstract), 10 (7.7\%) did not test the intervention, and 7 (5.4\%) addressed an adult population; 5 (3.8\%) did not use AI in the intervention, $5(3.8 \%)$ did not focus on people with disability or other diagnosed health conditions, and $4(3.1 \%)$ were not written in English (Figure 1).

\section{Type of Included Research}

The 94 included studies were published between 2000 and 2021, with a higher proportion published after 2010 (76/94, 81\%; Multimedia Appendix 2 [35-128]). All studies included AI as part of their intervention and targeted children or youth participation, as described in their research aims, outcomes, or as their focus of the tested AI application.

As for sample characteristics, the described interventions were evaluated on sample sizes ranging from 1 to 120 children and youth with an average of 14 children or youth. Of the included studies that reported on gender identity, 76\% (51/67) had a higher proportion of boys represented in their sample. A total of $92 \%(86 / 94)$ of the included studies did not report on the socioeconomic background of the family, parental education, or child or youth race or ethnicity. In total, 15\% (14/94) of studies sampled caregivers, teachers, peers, other school staff, or combinations thereof, in addition to children or youth when evaluating the intervention. Included interventions were developed or tested for children or youth with a broad range of diagnoses, with ASD being the most prevalent (43/94, 46\%), followed by cerebral palsy (CP; 18/94, 19\%).

\section{Types of AI Intervention, Mode of Intervention Delivery, and Type of Personalization}

Most of the 94 included studies used robotics as the type of AI intervention to target participation among children and youth with disabilities or other diagnosed health conditions (72/94, $77 \%$ ) [35-106], followed by HMI (51/94, 54\%) [35, 37-44, 47, 50-55, 58, 65, 66, 69, 71, 72, 75, 78, 80, 82, 85-89, 91-98, 100, 101, 103-111], visualization and VR (19/94, 20\%) $[53,54,72,79,107,108,112-124], \quad$ NLP $\quad(18 / 94, \quad 19 \%)$ $[36,47,52,64,71,78,79,82,91,101,103-105,120,125-128], \quad M L$ $(11 / 94,12 \%)$, computer vision (10/94, 11\%) $[40,41,64,67,69,107,110,120,125,126,128]$, and constraint satisfaction and optimization $(1 / 94,1 \%$; Table 1) [110]. Of the 72 studies on robotics, 63 (88\%) studies focused on the system of use $[35-39,41-53,55,57,58,60-63,65,66,68-74,76-78$, $80-101,103-106]$ and 9 (13\%) focused on robot mechanics [40,54,56,59,64,67,75,79,102]. 
Table 1. Delivery of participation-focused rehabilitation interventions that include artificial intelligence (AI).

\begin{tabular}{|c|c|c|c|}
\hline Type of AI & Personalization & Mode of delivery & $\begin{array}{l}\text { Addresses individ- } \\
\text { ual goal-setting }\end{array}$ \\
\hline Robotics: 72 [35-106] & $\begin{array}{ll}\text { - } & \text { Implicit + individuated: } 0 \\
\text { Implicit + categorical: } 37 \text { [35, 36, 38, } \\
\text { 43-46, 48-50, 52, 55-57, 60, 64-66, 70, } \\
\text { 74-77, 79, 81-84, 87, 89-91, 97, 101, } \\
\quad \text { 104-106] } \\
\text { - Explicit + individuated: } 0 \\
\text { Explicit + categorical: } 35 \text { [37, 39-42, } \\
\quad \text { 47, 51, 53, 54, 58, 59, 61-63, 67-69, } \\
71-73,78,80,85,86,88,92-96, \\
\quad 98-100,102,103]\end{array}$ & $\begin{array}{ll}\text { - } & \text { In-person: } 67 \\
& {[35-50,52-84,86-91,93,94,96-99,101-106]} \\
\text { - } & \text { Remote: } 5[51,85,92,95,100]\end{array}$ & 0 \\
\hline $\begin{array}{l}\text { Human-machine interaction: } 51[35 \text {, } \\
37-44,47,50-55,57,58,65,66,69, \\
71,72,75,78,80,82,85-89,91-98, \\
100,101,103-111]\end{array}$ & $\begin{array}{ll}\text { - } & \text { Implicit + individuated: } 1[110] \\
\text { Implicit + categorical: } 21[35,38,43, \\
\text { 44, 50, 52, 55, 57, 65, 66, 75, 82, 87, } \\
\text { 89, 91, 97, 101, 104-107] } \\
\text { Explicit + individuated: } 0 \\
\text { - } \\
\text { Explicit + categorical: } 29[37,39-42, \\
\quad 47,51,53,54,58,69,71,72,78,80, \\
85,86,88,92-96,98,100,103,108, \\
109,111]\end{array}$ & $\begin{array}{l}\text { In-person: } 44[35,37-44,47,50, \\
\text { 52-55, 57, 58, 65, 66, 69, 71, 72, 75, } \\
\text { 78, 80, 82, 86-89, 91, 93, 94, 96-98, } \\
\text { 101, 103-107, 109, 111] } \\
\text { - Remote: } 7[51,85,92,95,100,108,110]\end{array}$ & 0 \\
\hline $\begin{array}{l}\text { Visualization and virtual reality: } 19 \\
{[53,54,72,79,107,108,112-124]}\end{array}$ & $\begin{array}{ll}\text { - } & \text { Implicit + individuated: } 0 \\
\text { - } & \text { Implicit + categorical: } 5 \\
& {[79,107,114,117,120]} \\
\text { - } & \text { Explicit + individuated: } 0 \\
\text { - } & \text { Explicit + categorical: } 14 \\
& {[53,54,72,108,112,113,115,116,118,119,121-124]}\end{array}$ & $\begin{array}{l}\text { - In-person: } 18 \\
\text { - } \quad \text { Remote: } 1[108]\end{array}$ & $1[112]$ \\
\hline $\begin{array}{l}\text { Natural language processing: } 18[36, \\
47,52,64,71,78,79,82,91,101, \\
103-105,120,125-128]\end{array}$ & $\begin{array}{ll}\text { - } & \text { Implicit + individuated: } 0 \\
\text { - } & \text { Implicit + categorical: } 14 \\
& {[36,52,64,79,82,91,101,104,105,120,125-128]} \\
\text { - } & \text { Explicit + individuated: } 0 \\
\text { - } & \text { Explicit + categorical: } 4 \text { [47,71,78,103] }\end{array}$ & $\begin{array}{ll}\text { - } & \text { In-person: } 15 \\
& {[36,47,52,64,71,78,79,82,91,101,103-105,120,127]} \\
\text { - } & \text { Remote: } 3[125,126,128]\end{array}$ & 0 \\
\hline $\begin{array}{l}\text { Machine learning: } 11 \\
{[40,41,64,67,69,107,110,120,125,126,128]}\end{array}$ & $\begin{array}{ll}\text { - } & \text { Implicit + individuated: } 1[110] \\
\text { - } & \text { Implicit + categorical: } 6 \\
& {[64,107,120,125,126,128]} \\
\text { - } & \text { Explicit + individuated: } 0 \\
\text { - } & \text { Explicit + categorical: } 4[40,41,67,69]\end{array}$ & $\begin{array}{l}\text { - In-person: } 7[40,41,64,67,69,107,120] \\
\text { - } \quad \text { Remote: } 4[110,125,126,128]\end{array}$ & 0 \\
\hline $\begin{array}{l}\text { Computer vision: } 10 \\
{[35,39,58,63,65,69,75,112,120,127]}\end{array}$ & $\begin{array}{ll}\text { - } & \text { Implicit + individuated: } 0 \\
& \text { Implicit + categorical: } 5 \\
& {[35,65,75,120,127]} \\
\text { - } & \text { Explicit + individuated: } 0 \\
\text { - } & \text { Explicit + categorical: } 5 \\
& {[39,58,63,69,112]}\end{array}$ & $\begin{array}{ll}\text { - } & \text { In-person: } 10 \\
& {[35,39,58,63,65,69,75,112,120,127]} \\
\text { - } & \text { Remote: } 0\end{array}$ & $1[112]$ \\
\hline $\begin{array}{l}\text { Constraint satisfaction and optimiza- } \\
\text { tion: } 1 \text { [110] }\end{array}$ & $\begin{array}{ll}\text { - } & \text { Implicit + individuated: } 1 \text { [110] } \\
\text { - } & \text { Implicit + categorical: } 0 \\
\text { - } & \text { Explicit + individuated: } 0 \\
\quad & \text { Explicit + categorical: } 0\end{array}$ & $\begin{array}{l}\text { - } \quad \text { In-person: } 0 \\
\text { - }\end{array}$ & 0 \\
\hline $\begin{array}{l}\text { Human computation and crowdsourc- } \\
\text { ing: } 0\end{array}$ & $\mathrm{~N} / \mathrm{A}^{\mathrm{a}}$ & N/A & N/A \\
\hline Planning, routing, and scheduling: 0 & N/A & N/A & N/A \\
\hline Cognitive modeling: 0 & N/A & N/A & N/A \\
\hline Game theory: 0 & N/A & N/A & N/A \\
\hline
\end{tabular}

${ }^{\mathrm{a}} \mathrm{N} / \mathrm{A}$ : not applicable.

Most of the included studies described interventions using HMI [35-44, 47, 50-55, 57, 58, 63-67, 69, 71, 72, 75, 78-80, multiple applications of AI $(60 / 94,64 \%)$, such as robotics with $\quad 82,85-89,91-98,100,101,103-108,112,120,125-128]$, or 
ML with NLP and constraint satisfaction and optimization [110]. Across these studies, robotics was most often integrated into interventions that employed multiple applications of AI. Examples of multiple AI interventions that include robotics are humanoid or nonhumanoid devices to facilitate interaction or play of children with disabilities by directing the robot head toward a target or rocking its body from left to right to express emotions such as excitement [39].

Out of the included 94 studies, 22 (23\%) studies used forms of AI other than robotics [107-128]. Of these, 15 included visualization and VR applications, such as an immersive virtual learning program $[107,108,112-124]$; $8 \%$ (7/94) of interventions included neither robotics nor visualization and VR [109-111,125-128]. Examples of such interventions are a framework for speech-to-sign language translation for children with hearing impairments [127] and the design of a virtual space for hospitalized children to meet with their peers [108].

As for mode of delivery, most of the included studies described an intervention delivered in-person (84/94, 89\%) [35-50,52-84,86-91,93,94,96-99,101-107,109,111-124,127], mainly using a one-on-one approach. A total of $11 \%(10 / 94)$ of included studies evaluated an AI intervention that was delivered remotely [51,85,92,95,100,108,110,125,126,128].

Most AI interventions were tailored to a category of individuals (ie, categorical personalization) such as by a diagnostic group (93/94, 99\%) [35-109,111-128], using implicit (ie, automatically personalized: 45/94, 48\%) [35, 36, 38, 43-46, 48-50, 52, 55-57, 60, 64-66, 70, 74-77, 79, 81-84, 87, 89-91, 97, 101, 104-107, $114,117,120,125-128]$ or explicit (ie, manually personalized: 48/94, 51\%) approaches [37, 39-42, 47, 51, 53, 54, 58, 59, 61-63, 67-69, 71-73, 78, 80, 85, 86, 88, 92-96, 98-100, 102, $103,108,109,111-113,115,116,118,119,121-124]$. For example, Yee et al [35] designed a robotic platform for children with ASD by tailoring it to the needs typically described by this diagnostic group. In contrast, only $1 \%$ (1/94) of the included studies described an intervention that was tailored to the individually reported and unique needs of the child or youth with a disability or other diagnosed health condition (ie, individuated personalization) [110]. It included the use of a recommender algorithm, integrating information about the location of different physical and virtual learning resources, their purposes, modality, as well as the individual's class schedules, university rooms, and navigation system to suggest suitable and uniquely tailored options for access and navigation to the appropriate location [110]. In addition, 1\% (1/94) of the included interventions described individual goal-setting as part of their therapy process or intervention planning [112]. In this intervention, the Canadian Occupational Performance Measure was used for individual goal-setting and a video game-based task-oriented activity training was performed according to the defined patient goal [112].

\section{Discussion}

\section{Principal Findings}

This study summarizes 2 decades of evidence on the use of AI across interventions targeting the participation of children and youth with disabilities or other diagnosed health conditions, extending knowledge on the breadth of using AI in pediatric rehabilitation. There is an increased interest in AI applications for customizing pediatric rehabilitation services to individual child and family reported needs and reducing provider burden. The results of this review suggest that AI applications designed for children of diverse ages and diagnoses tend to emphasize robotics (alone or in combination with other forms of $\mathrm{AI}$ ), in-person delivery, and targeted groups of children using implicit and explicit personalization approaches. Each finding is further discussed to identify knowledge gaps that warrant future research.

Most of the studied robotic devices are not commercially available and were used during on-site therapy sessions to train a child or youth to participate in a specific activity, with an expected transfer or carryover of that gain into the child or youth's natural environment of home, school, or community. This expectation has been challenged in previous participation literature, emphasizing the importance of environments for shaping a young person's participation in daily activities [129-132]. The mediating role of the environment and context for child and youth participation has also been supported in research examining the effect of participation-focused interventions [133,134].

Interestingly, most of the found interventions were delivered in-person, despite the potential for leveraging technology to deliver rehabilitation interventions remotely. This result is in line with a previously conducted survey, which indicated that only $8 \%$ of Americans used telemedicine in 2019 [135]. Alternatively, our results might also be due to the high prevalence of interventions using robotics, often requiring the presence of trained operators and specialized equipment on the therapy site $[48,52,84]$. Remotely delivered interventions using robotics deploy robots in classrooms to enable virtual inclusion of home-bound children [51,85,92,95,100]. The remaining remotely delivered interventions commonly apply ML and NLP, potentially indicating the suitability of ML and NLP for use in remote pediatric rehabilitation interventions using AI. ML and NLP have been used in a range of health interventions to promote behavioral changes, such as physical activity and healthy diet, including goal-setting [136,137]. Given the existing evidence on the use of AI for goal-setting in other health care domains $[136,137]$ and the importance of gaining efficiency in enacting the complex process of goal-setting in pediatric rehabilitation $[138,139]$, the lack of attention to goal-setting in this review indicates a clear knowledge gap warranting future research. Emerging electronic participation-focused interventions such as the Participation and Environment Measure-Plus [140-143] with individual goal-setting as an integral part of their intervention might benefit from exploring the use of AI to fill this knowledge gap.

Most of the identified AI applications were tailored to the needs of groups of individuals, with only $1 \%$ (1/94) being tailored to the individually reported participation needs of children and youth with disabilities or other diagnosed health conditions. When comparing this result with the use of AI in fields outside of health care, it is surprising. For example, in marketing, AI has revolutionized common advertisement practices by tailoring 
advertisements to the reported needs and preferences of clients. This discrepancy between fields might be due to stricter protection of health information; however, there is an increase in similar advancements using data collected from patients in formal (eg, electronic health records) or informal (eg, patient dialog) settings, such as for diagnosing and decision-making [144-148]. Similar approaches might also be possible and beneficial within pediatric rehabilitation, using existing patient data to predict tailored participation-focused interventions. A recent systematic literature review on the effects of participation-focused interventions recommends focusing on individually tailored interventions to support the participation of children and youth with disabilities [20]. One way to tailor rehabilitation interventions to the reported needs of patients involves the patient's goals. In rehabilitation, goal-setting has become an integral part of the therapy process across professions, including pediatric participation-focused interventions [133,134]. Previous research has shown that caregivers can be guided to create participation-focused goals on the web [149]. Including goal-setting in AI-supported pediatric rehabilitation interventions might be an important first step to enable tailoring interventions to the participation needs of children and youth with disabilities or other diagnosed health conditions.

Despite the high prevalence of included studies testing or designing interventions for children and youth with ASD or cerebral palsy, a diverse sample in terms of diagnoses was represented in this scoping review, indicating relevance for the use of AI applications across diagnoses. In contrast, only $9 \%$ (8/94) of studies reported on child or youth race or ethnicity, family socioeconomic status, parental education, or family income, despite evidence indicating its influence on child and youth participation [150-152]. Future research should capture child and youth race and ethnicity as well as indicators of socioeconomic family status to describe the diversity of their study sample [153].

\section{Limitations}

An effort was made to conduct a comprehensive review of the literature pertaining to the use of AI to target children and youth participation. However, the results of this scoping review should be interpreted in light of some limitations. Despite the relatively high number of included studies, we may have missed some relevant documents. Three primary examples include (1) if an intervention using AI was not identified as such during the screening of titles and abstracts, the document was likely excluded from the search or selection process; (2) screening of reference lists was undertaken for review articles versus all included studies; and (3) documents published in languages other than English were excluded. In addition, the included studies were not screened based on their definition of participation, potentially leading to conceptual inconsistency, as has been shown in a systematic review of participation-focused interventions for children with disabilities [20]. Variability in the conceptualization of participation can limit the interpretation and comparison of results across studies $[20,154]$ to identify knowledge gaps specific to participation-focused rehabilitation interventions. Future research should map studies using AI to contemporary frameworks of the participation concept to ensure the interpretability of results across studies.

\section{Conclusions}

There is an increasing amount of research on interventions using AI to target the participation of children and youth with disabilities or other diagnosed health conditions, supporting the potential of using AI in pediatric rehabilitation. Overall, most interventions used multiple AI applications, including robotics and HMI. Other types of AI, such as ML or NLP, were less prevalent but showed potential benefits in participation-focused intervention. On the basis of our results, 3 major gaps were identified, warranting the need for future research and development: (1) a lack of remotely provided participation-focused interventions using AI; (2) a lack of individual goal-setting integrated in interventions using AI; and (3) a lack of interventions using AI tailored to individually reported participation needs of children, youth, or families.

In addition, future research should consistently report on the socioeconomic background of the family, parental education, or race and ethnicity to describe the diversity of their study sample.

\section{Acknowledgments}

The authors acknowledge Kyle A Truevillian for assisting with full-text screening of documents for this review and Amelia Brunskill at the University of Illinois at Chicago library for guidance on search strategies for undertaking this review. The authors also thank Vivian Villegas and Varun Maheshwari from the Children's Participation and Environment Research Lab at the University of Illinois at Chicago for critical feedback on prior drafts. This work was conducted in partial fulfillment of the requirements for a PhD in Rehabilitation Sciences and was funded by the University of Illinois at Chicago, through their Dean's Scholar Fellowship (principal investigator: VCK) and Chancellor's Undergraduate Research Award (ZS). We acknowledge the Research Open Access Publishing Fund of the University of Illinois at Chicago for financial support toward the open access publishing fee for this study.

\section{Conflicts of Interest}

None declared.

\section{Multimedia Appendix 1}

Search history in the included databases. 


\section{Multimedia Appendix 2}

Included studies.

[PDF File (Adobe PDF File), 98 KB-Multimedia Appendix 2]

\section{References}

1. Wang S, Blazer D, Hoenig H. Can ehealth technology enhance the patient-provider relationship in rehabilitation? Arch Phys Med Rehabil 2016 Sep;97(9):1403-1406. [doi: 10.1016/j.apmr.2016.04.002] [Medline: 27109332]

2. Lowes LP, Noritz GH, Newmeyer A, Embi PJ, Yin H, Smoyer WE, 'Learn from Every Patient' Study Group. 'Learn From Every Patient': implementation and early results of a learning health system. Dev Med Child Neurol 2017 Feb 22;59(2):183-191 [FREE Full text] [doi: 10.1111/dmcn.13227] [Medline: 27545839]

3. Stevenson RD. Integration of research and clinical practice: the future is now. Dev Med Child Neurol 2017 Feb 16;59(2):119-120 [FREE Full text] [doi: 10.1111/dmcn.13281] [Medline: 27634036]

4. Cacioppo M, Bouvier S, Bailly R, Houx L, Lempereur M, Mensah-Gourmel J, ECHO Group. Emerging health challenges for children with physical disabilities and their parents during the COVID-19 pandemic: The ECHO French survey. Ann Phys Rehabil Med 2021 Aug 18;64(3):101429 [FREE Full text] [doi: 10.1016/j.rehab.2020.08.001] [Medline: 32818674]

5. Eunice Kennedy Shriver National Institute of Child Health and Human Development and the NIH Medical Rehabilitation Coordinating Committee. NIH Rehabilitation Plan 2020. URL: https://nichd.ideascalegov.com/a/campaign-home/51 [accessed 2021-01-21]

6. Eunice Kennedy Shriver National Institute of Child Health and Human Development and the NIH Medical Rehabilitation Coordinating Committee. NIH Rehabilitation Plan. Eunice Kennedy Shriver National Institute of Child Health and Human Development and the NIH Medical Rehabilitation Coordinating Committee. 2020. URL: https://nichd.ideascalegov.com/ a/campaign-home/51 [accessed 2021-01-21]

7. Russell S, Norvig P. Artificial Intelligence: A Modern Approach, 3rd Ed. New York: Pearson; 2015:1-1152.

8. Jette AM. Opening the black box of rehabilitation interventions. Phys Ther 2020 Jun 23;100(6):883-884. [doi: 10.1093/ptj/pzaa078] [Medline: 32585702]

9. Whyte J, Hart T. It's more than a black box; it's a Russian doll. Am J Phys Med Rehabil 2003 Aug;82(8):639-652. [doi: 10.1097/01.phm.0000078200.61840.2d] [Medline: 12872021]

10. Dejong G, Horn SD, Gassaway JA, Slavin MD, Dijkers MP. Toward a taxonomy of rehabilitation interventions: using an inductive approach to examine the "black box" of rehabilitation. Arch Phys Med Rehabil 2004 Apr;85(4):678-686. [doi: 10.1016/j.apmr.2003.06.033] [Medline: 15083447]

11. Sartorato F, Przybylowski L, Sarko DK. Improving therapeutic outcomes in autism spectrum disorders: enhancing social communication and sensory processing through the use of interactive robots. J Psychiatr Res 2017 Jul;90:1-11. [doi: 10.1016/j.jpsychires.2017.02.004] [Medline: 28213292]

12. Scassellati B, Admoni H, Matarić M. Robots for use in autism research. Annu Rev Biomed Eng 2012 Aug 15;14(1):275-294. [doi: 10.1146/annurev-bioeng-071811-150036] [Medline: 22577778]

13. van den Heuvel RJF, Lexis MAS, Gelderblom GJ, Jansens RML, de Witte LP. Robots and ICT to support play in children with severe physical disabilities: a systematic review. Disabil Rehabil Assist Technol 2016 Feb 02;11(2):103-116. [doi: 10.3109/17483107.2015.1079268] [Medline: 26330097]

14. World Health Organization. International Classification of Functioning, Disability and Health: Children and Youth Version: ICF-CY. Geneva: World Health Organization; 2007:1-322.

15. Imms C, Granlund M, Wilson PH, Steenbergen B, Rosenbaum PL, Gordon AM. Participation, both a means and an end: a conceptual analysis of processes and outcomes in childhood disability. Dev Med Child Neurol 2017 Jan 19;59(1):16-25 [FREE Full text] [doi: 10.1111/dmcn.13237] [Medline: 27640996]

16. Kaelin VC, Wallace ER, Werler MM, Collett BR, Khetani MA. Community participation in youth with craniofacial microsomia. Disabil Rehabil 2020 Jun 01:1-8. [doi: 10.1080/09638288.2020.1765031] [Medline: 32478589]

17. Kaelin VC, Wallace ER, Werler MM, Collett BR, Rosenberg J, Khetani MA. Caregiver perspectives on school participation among students with craniofacial microsomia. Am J Occup Ther 2021 Jan 28;75(2):1-10 [FREE Full text] [doi: 10.5014/ajot.2021.041277] [Medline: 33657352]

18. Khetani MA, Graham JE, Davies PL, Law MC, Simeonsson RJ. Psychometric properties of the young children's participation and environment measure. Arch Phys Med Rehabil 2015 Feb;96(2):307-316 [FREE Full text] [doi: 10.1016/j.apmr.2014.09.031] [Medline: 25449189]

19. Law M, Anaby D, Teplicky R, Khetani MA, Coster W, Bedell G. Participation in the home environment among children and youth with and without disabilities. Br J Occup Ther 2013 Feb 15;76(2):58-66. [doi:

$10.4276 / 030802213 \times 13603244419112]$ 
20. Adair B, Ullenhag A, Keen D, Granlund M, Imms C. The effect of interventions aimed at improving participation outcomes for children with disabilities: a systematic review. Dev Med Child Neurol 2015 Dec 24;57(12):1093-1104 [FREE Full text] [doi: 10.1111/dmcn.12809] [Medline: 26010935]

21. Peters MDJ, Godfrey C, McInerney P, Munn Z, Tricco AC, Khalil H. Chapter 11: Scoping reviews. In: Aromataris E, Munn Z, editors. JBI Manual for Evidence Synthesis. Australia: JBI - The University of Adelaide; 2020.

22. Tricco AC, Lillie E, Zarin W, O'Brien KK, Colquhoun H, Levac D, Tunçalp, et al. PRISMA extension for Scoping Reviews (PRISMA-ScR): checklist and explanation. Ann Intern Med 2018 Oct 02;169(7):467-473. [doi: 10.7326/m18-0850]

23. Kaelin VC, Valizadeh M, Salgado Z, Truevillian KA, Parde M, Khetani MA. Artificial intelligence in rehabilitation targeting participation of young persons with disabilities: a scoping review. Open Science Forum. 2020. URL: https://osf.io/wmkg8 [accessed 2021-09-21]

24. Higgins JPT, Thomas J, Chandler J, Cumpston M, Li T, Page MJ, et al, editors. Cochrane Handbook for Systematic Reviews of Interventions version 6.2 (updated February 2021). In: Cochrane Training. Hoboken, New Jersey, United States: Wiley-Blackwell; 2021. URL: www.training.cochrane.org/handbook

25. Centre for Reviews and Dissemination. Systematic Reviews: CRD's Guidance for Undertaking Reviews in Health Care. York: CRD, University of York; 2009.

26. O'Connor C, Joffe H. Intercoder reliability in qualitative research: debates and practical guidelines. Int J Qual Methods 2020 Jan 22;19:160940691989922. [doi: 10.1177/1609406919899220]

27. United Nations. Youth. URL: https://www.un.org/en/global-issues/youth [accessed 2020-05-24]

28. Peters MDJ, Marnie C, Tricco AC, Pollock D, Munn Z, Alexander L, et al. Updated methodological guidance for the conduct of scoping reviews. JBI Evid Synth 2020 Oct;18(10):2119-2126. [doi: 10.11124/JBIES-20-00167] [Medline: 33038124]

29. Berger E. CSRankings: Computer science rankings. 2020. URL: http://csrankings.org/\#/index?all [accessed 2021-09-18]

30. Conitzer V. Association for the Advancement of Artificial Intelligence. AAAI-19: Thirty-third AAAI conference on artificial intelligence 2019 Jul 17;33:9755-9759 [FREE Full text] [doi: 10.1609/aaai.v33i01.33019755]

31. Riener R. Rehabilitation robotics. FNT in Robotics 2013;3(1-2):1-137. [doi: 10.1561/2300000028]

32. Fan H, Poole MS. What is personalization? Perspectives on the design and implementation of personalization in information systems. J Organ Comput Electron Commer 2006 Jan;16(3-4):179-202. [doi: 10.1080/10919392.2006.9681199]

33. Scobbie L, Dixon D, Wyke S. Goal setting and action planning in the rehabilitation setting: development of a theoretically informed practice framework. Clin Rehabil 2011 May 03;25(5):468-482. [doi: 10.1177/0269215510389198] [Medline: 21131335]

34. Landis JR, Koch GG. The measurement of observer agreement for categorical data. Biometrics 1977 Mar;33(1):159. [doi: $10.2307 / 2529310]$

35. Yee AWH, Kee TY, Limbu DK, Jian ATH, Dung TA, Yuen AWC. Developing a robotic platform to play with pre-school autistic children in a classroom environment. In: Proceedings of the Workshop at SIGGRAPH Asia. 2012 Presented at: SA '12: SIGGRAPH Asia 2012; Nov 26 - 27, 2012; Singapore p. 81-86. [doi: 10.1145/2425296.2425311]

36. So W, Cheng C, Lam W, Huang Y, Ng K, Tung H, et al. A robot-based play-drama intervention may improve the joint attention and functional play behaviors of chinese-speaking preschoolers with autism spectrum disorder: a pilot study. $\mathrm{J}$ Autism Dev Disord 2020 Feb 26;50(2):467-481. [doi: 10.1007/s10803-019-04270-z] [Medline: $\underline{31655965]}$

37. Klein T, Gelderblom GJ, de Witte L, Vanstipelen S. Evaluation of short term effects of the IROMEC robotic toy for children with developmental disabilities. In: Proceedings of the IEEE International Conference on Rehabilitation Robotics. 2011

Presented at: IEEE International Conference on Rehabilitation Robotics; Jun 29 - July 1, 2011; Zurich, Switzerland p. 1-5. [doi: 10.1109/icorr.2011.5975406]

38. Ríos-Rincón AM, Adams K, Magill-Evans J, Cook A. Playfulness in children with limited motor abilities when using a robot. Phys Occup Ther Pediatr 2016 Nov 13;36(3):232-246. [doi: 10.3109/01942638.2015.1076559] [Medline: 26566226]

39. Kozima H, Nakagawa C, Yasuda Y. Children-robot interaction: a pilot study in autism therapy. Prog Brain Res 2007;164:385-400. [doi: 10.1016/S0079-6123(07)64021-7]

40. Javed H, Park CH. Interactions with an empathetic agent: regulating emotions and improving engagement in autism. IEEE Robot Automat Mag 2019 Jun;26(2):40-48. [doi: 10.1109/mra.2019.2904638]

41. Javed H, Burns R, Jeon M, Howard AM, Park CH. A robotic framework to facilitate sensory experiences for children with autism spectrum disorder: a preliminary study. ACM Trans Hum Robot Interact 2019 Dec 31;9(1):1-26 [REE Full text] [doi: 10.1145/3359613] [Medline: 33829148]

42. Iacono I, Lehmann H, Marti P, Robins B, Dautenhahn K. Robots as social mediators for children with autism - a preliminary analysis comparing two different robotic platforms. In: Proceedings of the IEEE International Conference on Development and Learning (ICDL). 2011 Presented at: IEEE International Conference on Development and Learning (ICDL); Aug 24-27, 2011; Frankfurt am Main, Germany. [doi: 10.1109/devlrn.2011.6037322]

43. Goodrich MA, Colton MA, Brinton B, Fujiki M. A case for low-dose robotics in autism therapy. In: Proceedings of the 6th International Conference on Human-Robot Interaction. 2011 Presented at: HRI'11: International Conference on Human-Robot Interaction; Mar 6 - 9, 2011; Lausanne, Switzerland p. 143-144. [doi: 10.1145/1957656.1957702] 
44. Gilliaux M, Renders A, Dispa D, Holvoet D, Sapin J, Dehez B, et al. Upper limb robot-assisted therapy in cerebral palsy: a single-blind randomized controlled trial. Neurorehabil Neural Repair 2015 Feb 11;29(2):183-192. [doi: 10.1177/1545968314541172] [Medline: 25015650]

45. Cook AM, Bentz B, Harbottle N, Lynch C, Miller B. School-based use of a robotic arm system by children with disabilities. IEEE Trans Neural Syst Rehabil Eng 2005 Dec;13(4):452-460. [doi: 10.1109/tnsre.2005.856075]

46. Conchinha C, Osório P, de Freitas JC. Playful learning: educational robotics applied to students with learning disabilities. In: Proceedings of the 2015 International Symposium on Computers in Education (SIIE). 2015 Presented at: International Symposium on Computers in Education (SIIE); Nov 25-27, 2015; Setubal, Portugal p. 167-171. [doi: 10.1109/siie.2015.7451669]

47. Silvera-Tawil D, Bradford D, Roberts-Yates C. Talk to me: the role of human-robot interaction in improving verbal communication skills in students with autism or intellectual disability. In: Proceedings of the 27th IEEE International Symposium on Robot and Human Interactive Communication (RO-MAN). 2018 Presented at: 27th IEEE International Symposium on Robot and Human Interactive Communication (RO-MAN); Aug 27-31, 2018; Nanjing, China. [doi: 10.1109/roman.2018.8525698]

48. Bonarini A, Clasadonte F, Garzotto F, Gelsomini M, Romero M. Playful interaction with Teo, a mobile robot for children with neurodevelopmental disorders. In: Proceedings of the 7th International Conference on Software Development and Technologies for Enhancing Accessibility and Fighting Info-exclusion. 2016 Presented at: DSAI 2016: 7th International Conference on Software Development and Technologies for Enhancing Accessibility and Fighting Info-exclusion; Dec 1 - 3, 2016; Vila Real Portugal p. 223-231. [doi: 10.1145/3019943.3019976]

49. Besio S, Bonarini A, Lynch H, Molina P, Veronese F, Bulgarelli D. Mainstream robotic toys and children with physical impairment: what about playfulness? In: Proceedings of the 7th International Conference on Software Development and Technologies for Enhancing Accessibility and Fighting Info-exclusion. 2016 Presented at: DSAI 2016: 7th International Conference on Software Development and Technologies for Enhancing Accessibility and Fighting Info-Exclusion; Dec 1 - 3, 2016; Vila Real Portugal p. 208-215. [doi: 10.1145/3019943.3019974]

50. Aslam S, Standen PJ, Shopland N, Burton A, Brown D. A comparison of humanoid and non-humanoid robots in supporting the learning of pupils with severe intellectual disabilities. In: Proceedings of the International Conference on Interactive Technologies and Games (ITAG). 2016 Presented at: International Conference on Interactive Technologies and Games (ITAG); Oct 26-27, 2016; Nottingham, UK p. 7-12. [doi: 10.1109/itag.2016.9]

51. Newhart VA, Warschauer M, Sender L. Virtual inclusion via telepresence robots in the classroom: an exploratory case study. Int J Technol Learn 2016;23(4):9-25. [doi: 10.18848/2327-0144/cgp/v23i04/9-25]

52. Adams K, Cook A. Using robots in "Hands-on" academic activities: a case study examining speech-generating device use and required skills. Disabil Rehabil Assist Technol 2016 Dec 11;11(5):433-443. [doi: 10.3109/17483107.2014.986224] [Medline: 25495803]

53. Welch KC, Lahiri U, Warren Z, Sarkar N. An approach to the design of socially acceptable robots for children with autism spectrum disorders. Int J of Soc Robotics 2010 Jul 7;2(4):391-403. [doi: 10.1007/s12369-010-0063-X]

54. Wainer J, Dautenhahn K, Robins B, Amirabdollahian F. A pilot study with a novel setup for collaborative play of the humanoid robot Kaspar with children with autism. Int J of Soc Robotics 2013 Sep 11;6(1):45-65. [doi: 10.1007/s12369-013-0195-x]

55. Stanton CM, Kahn PH, Severson RL, Ruckert JH, Gill BT. Robotic animals might aid in the social development of children with autism. In: Proceedings of the 3rd ACM/IEEE international conference on Human robot interaction. 2008 Presented at: HRI '08: International Conference on Human Robot Interaction; Mar 12 - 15, 2008; Amsterdam, The Netherlands p. 271-278. [doi: $10.1145 / 1349822.1349858]$

56. Pulido JC, González JC, Suárez-Mejías C, Bandera A, Bustos P, Fernández F. Evaluating the child-robot interaction of the naotherapist platform in pediatric rehabilitation. Int J of Soc Robotics 2017 Apr 8;9(3):343-358. [doi: 10.1007/s12369-017-0402-2]

57. Pliasa S, Fachantidis N. Can a robot be an efficient mediator in promoting dyadic activities among children with Autism Spectrum Disorders and children of Typical Development? In: Proceedings of the 9th Balkan Conference on Informatics. 2019 Presented at: BCI'19: 9th Balkan Conference in Informatics; Sept 26 - 28, 2019; Sofia, Bulgaria p. 1-6. [doi: $10.1145 / 3351556.3351592]$

58. Rudovic O, Utsumi Y, Lee J, Hernandez J, Castelló Ferrer E, Schuller B, et al. Culturenet: a deep learning approach for engagement intensity estimation from face images of children with autism. In: Proceedings of the IEEE/RSJ International Conference on Intelligent Robots and Systems (IROS). 2018 Presented at: IEEE/RSJ International Conference on Intelligent Robots and Systems (IROS); Oct 1-5, 2018; Madrid, Spain p. 339-346. [doi: 10.1109/iros.2018.8594177]

59. Marti P. Bringing playfulness to disabilities. In: Proceedings of the 6th Nordic Conference on Human-Computer Interaction: Extending Boundaries. 2010 Presented at: NordiCHI '10: 6th Nordic Conference on Human-Computer Interaction; Oct 16 - 20, 2010; Reykjavik, Iceland p. 851-856. [doi: 10.1145/1868914.1869046]

60. Ludi S, Bernstein D, Mutch-Jones K. Enhanced robotics!: improving building and programming learning experiences for students with visual impairments. In: Proceedings of the 49th ACM Technical Symposium on Computer Science Education. 
2018 Presented at: SIGCSE '18: The 49th ACM Technical Symposium on Computer Science Education; Feb 21 - 24, 2018 ; Baltimore, USA p. 372-377. [doi: 10.1145/3159450.3159501]

61. Lindsay S, Lam A. Exploring types of play in an adapted robotics program for children with disabilities. Disabil Rehabil Assist Technol 2018 Apr 28;13(3):263-270. [doi: 10.1080/17483107.2017.1306595] [Medline: 28350526]

62. Lindsay S, Hounsell KG. Adapting a robotics program to enhance participation and interest in STEM among children with disabilities: a pilot study. Disabil Rehabil Assist Technol 2017 Oct 20;12(7):694-704. [doi: 10.1080/17483107.2016.1229047] [Medline: 27762644]

63. Kozima H, Michalowski MP, Nakagawa C. Keepon: a playful robot for research, therapy, and entertainment. Int J of Soc Robotics 2009 Nov 19;1(1):3-18. [doi: 10.1007/s12369-008-0009-8]

64. Kokkoni E, Mavroudi E, Zehfroosh A, Galloway JC, Vidal R, Heinz J, et al. GEARing smart environments for pediatric motor rehabilitation. J Neuroeng Rehabil 2020 Feb 10;17(1):1-15 [FREE Full text] [doi: 10.1186/s12984-020-0647-0] [Medline: $\underline{\text { 32041623] }}$

65. Koch SA, Stevens CE, Clesi CD, Lebersfeld JB, Sellers AG, McNew ME, et al. A feasibility study evaluating the emotionally expressive robot SAM. Int J of Soc Robotics 2017 Jun 23;9(4):601-613. [doi: 10.1007/s12369-017-0419-6]

66. Kim ES, Daniell CM, Makar C, Elia J, Scassellati B, Shic F. Potential clinical impact of positive affect in robot interactions for autism intervention. In: Proceedings of the International Conference on Affective Computing and Intelligent Interaction (ACII). 2015 Presented at: International Conference on Affective Computing and Intelligent Interaction (ACII); Sept 21-24, 2015; Xi'an, China. [doi: 10.1109/acii.2015.7344544]

67. Khamassi M, Chalvatzaki G, Tsitsimis T, Velentzas G, Tzafestas C. A framework for robot learning during child-robot interaction with human engagement as reward signal. In: Proceedings of the 27th IEEE International Symposium on Robot and Human Interactive Communication (RO-MAN). 2018 Presented at: 27th IEEE International Symposium on Robot and Human Interactive Communication (RO-MAN); Aug 27-31, 2018; Nanjing, China p. 461-464. [doi:

10.1109/roman.2018.8525598]

68. Jung SE, Lee K, Cherniak S, Cho E. Non-sequential learning in a robotics class: insights from the engagement of a child with autism spectrum disorder. Tech Know Learn 2019 Jan 23;25(1):63-81. [doi: 10.1007/s10758-018-9394-8]

69. Pioggia G, Igliozzi R, Sica ML, Ferro M, Muratori F, Ahluwalia A, et al. Exploring emotional and imitational android-based interactions in autistic spectrum disorders. J CyberTher Rehabil 2008;1(1):49-61 [FREE Full text]

70. Haumont T, Rahman T, Sample W, M King M, Church C, Henley J, et al. Wilmington robotic exoskeleton: a novel device to maintain arm improvement in muscular disease. J Pediatr Orthop 2011 ;31(5):e44-e49. [doi:

10.1097/BPO.0b013e31821f50b5] [Medline: 21654447]

71. Ferm UM, Claesson BK, Ottesjö C, Ericsson S. Participation and enjoyment in play with a robot between children with cerebral palsy who use AAC and their peers. Augment Altern Commun 2015 Jun 29;31(2):108-123. [doi: 10.3109/07434618.2015.1029141] [Medline: 25921358]

72. Encarnação P, Leite T, Nunes C, Nunes da Ponte M, Adams K, Cook A, et al. Using assistive robots to promote inclusive education. Disabil Rehabil Assist Technol 2017 May 26;12(4):352-372. [doi: 10.3109/17483107.2016.1167970] [Medline: 27115833]

73. Cook A, Howery K, Gu J, Meng M. Robot enhanced interaction and learning for children with profound physical disabilities. Technol Disabil 2001 May 14;13(1):1-8. [doi: 10.3233/tad-2000-13101]

74. Buitrago JA, Bolaños AM, Caicedo Bravo E. A motor learning therapeutic intervention for a child with cerebral palsy through a social assistive robot. Disabil Rehabil Assist Technol 2020 Apr 26;15(3):357-362. [doi:

10.1080/17483107.2019.1578999] [Medline: $\underline{\text { 30806105] }}$

75. Boccanfuso L, O'Kane JM. CHARLIE : an adaptive robot design with hand and face tracking for use in autism therapy. Int J of Soc Robotics 2011 Sep 24;3(4):337-347. [doi: 10.1007/s12369-011-0110-2]

76. Blanson Henkemans OA, Bierman BPB, Janssen J, Looije R, Neerincx MA, van Dooren MMM, et al. Design and evaluation of a personal robot playing a self-management education game with children with diabetes type 1. Int J Hum Comput Stud 2017 Oct;106:63-76. [doi: 10.1016/j.ijhcs.2017.06.001]

77. Blanson Henkemans OA, Bierman BPB, Janssen J, Neerincx MA, Looije R, van der Bosch H, et al. Using a robot to personalise health education for children with diabetes type 1: a pilot study. Patient Educ Couns 2013 Aug;92(2):174-181. [doi: 10.1016/j.pec.2013.04.012] [Medline: 23684366]

78. Barakova EI, Bajracharya P, Willemsen M, Lourens T, Huskens B. Long-term LEGO therapy with humanoid robot for children with ASD. Expert Syst 2014 Nov 13;32(6):698-709. [doi: 10.1111/exsy.12098]

79. Arpaia P, Duraccio L, Moccaldi N, Rossi S. Wearable brain-computer interface instrumentation for robot-based rehabilitation by augmented reality. IEEE Trans Instrum Meas 2020 Sep;69(9):6362-6371. [doi: 10.1109/tim.2020.2970846]

80. Marti P, Giusti L. A robot companion for inclusive games: a user-centred design perspective. In: Proceedings of the IEEE International Conference on Robotics and Automation. 2010 Presented at: IEEE International Conference on Robotics and Automation; May 3-7, 2010; Anchorage, US p. 4348-4353. [doi: 10.1109/robot.2010.5509385]

81. Alotaibi MH. The effectiveness of robot-assisted, task-specific ankle training in improving deficits across the three domains of the ICF in children with cerebral palsy (CP). Thesis and Dissertations - Indiana University. 2018. URL: https:/ /scholarworks.iupui.edu/handle/1805/17929 [accessed 2021-09-18] 
82. Santatiwongchai S, Kaewkamnerdpong B, Jutharee W, Ounjai W. BLISS: using robot in learning intervention to promote social skills for autism therapy. In: Proceedings of the International Convention on Rehabilitation Engineering \& Assistive Technology. 2016 Presented at: International Convention on Rehabilitation Engineering \& Assistive Technology; Jul 25 28, 2016; Midview City, Singapore p. 1-4. [doi: 10.5555/3014393.3014413]

83. Schroeder AS, Homburg M, Warken B, Auffermann H, Koerte I, Berweck S, et al. Prospective controlled cohort study to evaluate changes of function, activity and participation in patients with bilateral spastic cerebral palsy after robot-enhanced repetitive treadmill therapy. Eur J Paediatr Neurol 2014 Jul;18(4):502-510. [doi: 10.1016/j.ejpn.2014.04.012] [Medline: 24821475]

84. Bulgarelli D, Bianquin N, Besio S, Molina P. Children with cerebral palsy playing with mainstream robotic toys: playfulness and environmental supportiveness. Front Psychol 2018 Sep 26;9:1-9 [FREE Full text] [doi: 10.3389/fpsyg.2018.01814] [Medline: 30319509$]$

85. Soares N, Kay JC, Craven G. Mobile robotic telepresence solutions for the education of hospitalized children. Perspect Health Inf Manag 2017;14(Fall):1e [FREE Full text] [Medline: 29118682]

86. Alnajjar F, Cappuccio M, Renawi A, Mubin O, Loo CK. Personalized robot interventions for autistic children: an automated methodology for attention assessment. Int J of Soc Robotics 2020 Mar 06;13(1):67-82. [doi: 10.1007/s12369-020-00639-8]

87. Barnes JA, Park CH, Howard A, Jeon M. Child-robot interaction in a musical dance game: an exploratory comparison study between typically developing children and children with autism. Int J Hum Comput Interact 2021 Sep 14;37(3):249-266. [doi: 10.1080/10447318.2020.1819667] [Medline: 33767571]

88. Metatla O, Bardot S, Cullen M, Serrano M, Jouffrais C. Robots for inclusive play- co-designing an educational game with visually impaired and sighted children. In: Proceedings of the $2020 \mathrm{CHI}$ Conference on Human Factors in Computing Systems. 2020 Presented at: CHI '20: CHI Conference on Human Factors in Computing Systems; Apr 25 - 30, 2020 ; Honolulu, USA p. 1-13. [doi: 10.1145/3313831.3376270]

89. Ismail LI, Hanapiah FA, Belpaeme T, Dambre J, Wyffels F. Analysis of attention in child-robot interaction among children diagnosed with cognitive impairment. Int J of Soc Robotics 2020 Feb 03;13(2):141-152. [doi: 10.1007/s12369-020-00628-x]

90. Silva K, Lima M, Fafiães C, Sinval J, de Sousa L. Preliminary test of the potential of contact with dogs to elicit spontaneous imitation in children and adults with severe autism spectrum disorder. Am J Occup Ther 2020 Dec 05;74(1):1-8 [FREE Full text] [doi: $\underline{10.5014 / a j o t .2020 .031849}$ ] [Medline: $\underline{\text { 32078518] }}$

91. Marti P, Pollini A, Rullo A, Shibata T. Engaging with artificial pets. In: Proceedings of the 2005 Annual Conference on European Association of Cognitive Ergonomics. 2005 Presented at: Annual Conference on European Association of Cognitive Ergonomics; Sept 29 - October 1, 2005; Chania, Greece p. 99-106. [doi: 10.5555/1124666.1124680]

92. Weibel M, Nielsen MK, Topperzer MK, Hammer NM, Møller SW, Schmiegelow K, et al. Back to school with telepresence robot technology: a qualitative pilot study about how telepresence robots help school-aged children and adolescents with cancer to remain socially and academically connected with their school classes during treatment. Nurs Open 2020 Jul 12;7(4):988-997 [FREE Full text] [doi: 10.1002/nop2.471] [Medline: 32587717]

93. Neto I, Johal W, Couto M, Nicolau H, Paiva A, Guneysu A. Using tabletop robots to promote inclusive classroom experiences. In: Proceedings of the Interaction Design and Children Conference. 2020 Presented at: IDC '20: Interaction Design and Children; Jun 21 - 24, 2020; London, UK p. 281-292. [doi: 10.1145/3392063.3394439]

94. Costa S, Santos C, Soares F, Ferreira M, Moreira F. Promoting interaction amongst autistic adolescents using robots. In: Proceedings of the Annual International Conference of the IEEE Engineering in Medicine and Biology. 2010 Presented at: Annual International Conference of the IEEE Engineering in Medicine and Biology; Aug 31 - Sept. 4, 2010; Buenos Aires, Argentina p. 3856-3859. [doi: 10.1109/iembs.2010.5627905]

95. Fels DI, Waalen JK, Zhai S, Weiss PT. Telepresence under exceptional circumstances: enriching the connection to school for sick children. In: Proceedings of the IFIP TC13 International Conference on Human-Computer Interaction. 2001 Presented at: IFIP TC13 International Conference on Human-Computer Interaction; Jul 9-13, 2001; Tokyo, Japan p. 617-624 URL: https://dblp.org/rec/conf/interact/FelsWZW01.html

96. Kim E, Paul R, Shic F, Scassellati B. Bridging the research gap: making HRI useful to individuals with autism. J Human-Robot Interact 2012 Aug 01;1(1):26-54. [doi: 10.5898/jhri.1.1.kim]

97. Shamsuddin S, Yussof H, Ismail LI, Mohamed S, Hanapiah FA, Zahari NI. Initial response in HRI - a case study on evaluation of child with autism spectrum disorders interacting with a humanoid robot NAO. Procedia Eng 2012;41:1448-1455. [doi: 10.1016/j.proeng.2012.07.334]

98. Simut RE, Vanderfaeillie J, Peca A, Van de Perre G, Vanderborght B. Children with autism spectrum disorders make a fruit salad with probo, the social robot: an interaction study. J Autism Dev Disord 2016 Jan 25;46(1):113-126. [doi: 10.1007/s10803-015-2556-9] [Medline: 26304031]

99. Feng H. Xylo-Bot: a therapeutic robot-based music platform for children with autism. ProQuest Dissertations - University of Denver. 2020. URL: https://www.proquest.com/openview/16a69b9a20d3fc4d0929951844b2faf8/ 1 ?pq-origsite $=$ gscholar\&cbl=44156 [accessed 2021-09-20]

100. Ahumada-Newhart V, Olson JS. Going to school on a robot: robot and user interface design features that matter. ACM Trans Comput Hum Interact 2019 Jul 27;26(4):1-28 [FREE Full text] [doi: 10.1145/3325210] [Medline: 31692962] 
101. Miyamoto E, Lee M, Fujii H, Okada M. How can robots facilitate social interaction of children with autism?: possible implications for educational environments. In: Proceedings of the Fifth International Workshop on Epigenetic Robotics. 2005 Presented at: Fifth International Workshop on Epigenetic Robotics; 2005; Lund, Sweden p. 145-146 URL: http:/ lcogprints.org/4993/1/miyamoto.pdf

102. Ludi S, Reichlmayr T. The use of robotics to promote computing to pre-college students with visual impairments. ACM Trans Comput Educ 2011 Oct;11(3):1-20. [doi: 10.1145/2037276.2037284]

103. Zhanatkyzy A, Telisheva Z, Turarova A, Zhexenova Z, Sandygulova A. Quantitative results of robot-assisted therapy for children with autism, ADHD and delayed speech development. In: Proceedings of the Companion of the 2020 ACM/IEEE International Conference on Human-Robot Interaction. 2020 Presented at: HRI '20: ACM/IEEE International Conference on Human-Robot Interaction; Mar 23 - 26, 2020; Cambridge, UK p. 541-542. [doi: 10.1145/3371382.3378254]

104. Butchart J, Harrison R, Ritchie J, Martí F, McCarthy C, Knight S, et al. Child and parent perceptions of acceptability and therapeutic value of a socially assistive robot used during pediatric rehabilitation. Disabil Rehabil 2021 Jan 23;43(2):163-170. [doi: 10.1080/09638288.2019.1617357] [Medline: $\underline{31120794]}$

105. Ljunglöf P, Claesson B, Müller I, Ericsson S, Ottesjö C, Berman A, et al. Lekbot: a talking and playing robot for children with disabilities. In: Proceedings of the Second Workshop on Speech and Language Processing for Assistive Technologies. 2011 Presented at: Second Workshop on Speech and Language Processing for Assistive Technologies; Jul 30, 2011; Edinburgh, Scotland p. 110-119. [doi: 10.5555/2140499.2140516]

106. Lehmann H, Iacono I, Robins B, Marti P, Dautenhahn K. Make it move': playing cause and effect games with a robot companion for children with cognitive disabilities. In: Proceedings of the 29th Annual European Conference on Cognitive Ergonomics. 2011 Presented at: ECCE '11: European Conference on Cognitive Ergonomics; Aug 24 - 26, 2011; Rostock, Germany p. 105-112. [doi: 10.1145/2074712.2074734]

107. Bian D, Wade J, Swanson A, Weitlauf A, Warren Z, Sarkar N. Design of a physiology-based adaptive virtual reality driving platform for individuals with ASD. ACM Trans Access Comput 2019 Feb 23;12(1):1-24. [doi: 10.1145/3301498]

108. Bers MU, Gonzalez-Heydrich J, DeMaso DR. Identity construction environments: supporting a virtual therapeutic community of pediatric patients undergoing dialysis. In: Proceedings of the SIGCHI Conference on Human Factors in Computing Systems. 2001 Presented at: CHI01: Human Factors in Computing Systems; Mar 31 - Apr 5, 2001; Seattle, USA p. $380-387$. [doi: $10.1145 / 365024.365302]$

109. Porayska-Pomsta K, Alcorn AM, Avramides K, Beale S, Bernardini S, Foster ME, et al. Blending human and artificial intelligence to support autistic children's social communication skills. ACM Trans Comput-Hum Interact 2018 Dec 20;25(6):1-35. [doi: 10.1145/3271484]

110. Goldberg M, Karimi H, Pearlman JL. Interactive, Mobile, AGIle and Novel Education (IMAGINE): a conceptual framework to support students with mobility challenges in higher education. Disabil Rehabil Assist Technol 2016 Sep 12;11(1):50-60. [doi: 10.3109/17483107.2014.959074] [Medline: 25212492]

111. Kolne K, Bui S, Lindsay S. Assessing the environmental quality of an adapted, play-based LEGO robotics program to achieve optimal outcomes for children with disabilities. Disabil Rehabil 2020 Mar 25:1-10. [doi: 10.1080/09638288.2020.1743776] [Medline: 32208981]

112. Arman N, Tarakci E, Tarakci D, Kasapcopur O. Effects of video games-based task-oriented activity training (Xbox 360 Kinect) on activity performance and participation in patients with juvenile idiopathic arthritis. Am J Phys Med Rehabil 2019 Mar;98(3):174-181. [doi: 10.1097/phm.0000000000001001]

113. Reid DT. Benefits of a virtual play rehabilitation environment for children with cerebral palsy on perceptions of self-efficacy: a pilot study. Pediatr Rehabil 2002 Jul 10;5(3):141-148. [doi: 10.1080/1363849021000039344] [Medline: 12581476]

114. Miller S, Reid D. Doing play: competency, control, and expression. Cyberpsychol Behav 2003 Dec;6(6):623-632. [doi: 10.1089/109493103322725397] [Medline: 14756927]

115. Bonney E, Ferguson G, Smits-Engelsman B. The efficacy of two activity-based interventions in adolescents with developmental coordination disorder. Res Dev Disabil 2017 Dec;71:223-236. [doi: 10.1016/j.ridd.2017.10.013] [Medline: 29055242]

116. Green D, Wilson PH. Use of virtual reality in rehabilitation of movement in children with hemiplegia-a multiple case study evaluation. Disabil Rehabil 2012 Oct 06;34(7):593-604. [doi: 10.3109/09638288.2011.613520] [Medline: 21978233]

117. Mineo BA, Ziegler W, Gill S, Salkin D. Engagement with electronic screen media among students with autism spectrum disorders. J Autism Dev Disord 2009 Jan 15;39(1):172-187. [doi: 10.1007/s10803-008-0616-0] [Medline: 18626761]

118. Ke F, Im T. Virtual-reality-based social interaction training for children with high-functioning autism. J Educ Res 2013 Nov 02;106(6):441-461. [doi: 10.1080/00220671.2013.832999]

119. Reid D. The influence of virtual reality on playfulness in children with cerebral palsy: a pilot study. Occup Ther Int 2004 Aug;11(3):131-144. [doi: 10.1002/oti.202] [Medline: 15297894]

120. Lahiri U, Bekele E, Dohrmann E, Warren Z, Sarkar N. Design of a virtual reality based adaptive response technology for children with autism. IEEE Trans Neural Syst Rehabil Eng 2013 Jan;21(1):55-64. [doi: 10.1109/tnsre.2012.2218618]

121. Altizer Jr R, Handman E, Bayles G, Jackman J, Cheng K, Ritchie S, et al. Choreografish: co-designing a choreography-based therapeutic virtual reality system with youth who have autism spectrum advantages. In: Proceedings of the 2018 Annual Symposium on Computer-Human Interaction in Play Companion Extended Abstracts. 2018 Presented at: CHI PLAY '18: 
The annual symposium on Computer-Human Interaction in Play; Oct 28 - 31, 2018; Melbourne, Australia p. 381-389. [doi: $10.1145 / 3270316.3271541]$

122. Mei C, Mason L, Quarles J. 'I Built It!' - Exploring the effects of customizable virtual humans on adolescents with ASD. In: Proceedings of the IEEE Virtual Reality (VR). 2015 Presented at: IEEE Virtual Reality (VR); Mar 23-27, 2015; Arles, France p. 235-236. [doi: 10.1109/vr.2015.7223382]

123. Bortone I, Leonardis D, Solazzi M, Procopio C, Crecchi A, Bonfiglio L, et al. Integration of serious games and wearable haptic interfaces for neuro rehabilitation of children with movement disorders: a feasibility study. In: Proceedings of the International Conference on Rehabilitation Robotics (ICORR). 2017 Presented at: International Conference on Rehabilitation Robotics (ICORR); Jul 17-20, 2017; London, UK p. 1094-1099. [doi: 10.1109/icorr.2017.8009395]

124. Byrne J, Ip HHS, Lau K, Chen Li R, Tso A, Choi C. InSPAL: a novel immersive virtual learning programme. Stud Health Technol Inform 2015;219:129-134. [Medline: 26799893]

125. Rivas-Perez T, Meza-Vega A, Mora-Lezcano V, Palacio-Amador D, Chacón-Rivas M. EULER - Mathematical editing by voice input for people with visual impairment. In: Proceedings of the International Conference on Inclusive Technologies and Education (CONTIE). 2019 Presented at: International Conference on Inclusive Technologies and Education (CONTIE); Oct 30 - Nov. 1, 2019; San Jose del Cabo, Mexico p. 9-95. [doi: 10.1109/contie49246.2019.00012]

126. Black R, Waller A, Turner R, Reiter E. Supporting personal narrative for children with complex communication needs. ACM Trans Comput-Hum Interact 2012 Jul;19(2):1-35. [doi: 10.1145/2240156.2240163]

127. Otoom M, Alzubaidi MA. Ambient intelligence framework for real-time speech-to-sign translation. Assist Technol 2018 Feb 02;30(3):119-132. [doi: 10.1080/10400435.2016.1268218] [Medline: 28152342]

128. Beaudry J, Consigli A, Clark C, Robinson KJ. Getting ready for adult healthcare: designing a chatbot to coach adolescents with special health needs through the transitions of care. J Pediatr Nurs 2019 Nov;49:85-91. [doi: 10.1016/j.pedn.2019.09.004] [Medline: 31644960 ]

129. Anaby D, Hand C, Bradley L, DiRezze B, Forhan M, DiGiacomo A, et al. The effect of the environment on participation of children and youth with disabilities: a scoping review. Disabil Rehabil 2013 Sep 25;35(19):1589-1598. [doi: 10.3109/09638288.2012.748840] [Medline: 23350759]

130. Anaby D, Law M, Hanna S, Dematteo C. Predictors of change in participation rates following acquired brain injury: results of a longitudinal study. Dev Med Child Neurol 2012 Apr;54(4):339-346 [FREE Full text] [doi: 10.1111/j.1469-8749.2011.04204.x] [Medline: 22257122]

131. Albrecht EC, Khetani MA. Environmental impact on young children's participation in home-based activities. Dev Med Child Neurol 2017 Apr 17;59(4):388-394 [FREE Full text] [doi: 10.1111/dmcn.13360] [Medline: 27988938]

132. Houtrow A, Murphy N, Council on Children With Disabilities. Prescribing physical, occupational, and speech therapy services for children with disabilities. Pediatrics 2019 Apr 25;143(4):e20190285 [FREE Full text] [doi: 10.1542/peds.2019-0285] [Medline: 30910917]

133. Anaby DR, Law M, Feldman D, Majnemer A, Avery L. The effectiveness of the Pathways and Resources for Engagement and Participation (PREP) intervention: improving participation of adolescents with physical disabilities. Dev Med Child Neurol 2018 May 06;60(5):513-519 [FREE Full text] [doi: 10.1111/dmcn.13682] [Medline: 29405282]

134. Anaby DR, Law MC, Majnemer A, Feldman D. Opening doors to participation of youth with physical disabilities: an intervention study. Can J Occup Ther 2016 Apr 21;83(2):83-90. [doi: 10.1177/0008417415608653] [Medline: 26501799]

135. Telehealth index: 2019 Consumer survey. American Well Corporation. 2019. URL: https://static.americanwell.com/app/ uploads/2019/07/American-Well-Telehealth-Index-2019-Consumer-Survey-eBook2.pdf [accessed 2021-03-16]

136. Zhang J, Oh YJ, Lange P, Yu Z, Fukuoka Y. Artificial intelligence chatbot behavior change model for designing artificial intelligence chatbots to promote physical activity and a healthy diet: viewpoint. J Med Internet Res 2020 Sep 30;22(9):e22845 [FREE Full text] [doi: 10.2196/22845] [Medline: 32996892]

137. Gupta I, Eugenio B, Ziebart B, Liu B, Gerber B, Sharp L. Modeling health coaching dialogues for behavioral goal extraction. In: Proceedings of the IEEE International Conference on Bioinformatics and Biomedicine (BIBM). 2019 Presented at: IEEE International Conference on Bioinformatics and Biomedicine (BIBM); Nov 18-21, 2019; San Diego, USA p. $118-119$. [doi: 10.1109/bibm47256.2019.8983138]

138. Pritchard-Wiart L, Thompson-Hodgetts S, McKillop AB. A review of goal setting theories relevant to goal setting in paediatric rehabilitation. Clin Rehabil 2019 Sep 09;33(9):1515-1526. [doi: 10.1177/0269215519846220] [Medline: 31072123]

139. Brewer K, Pollock N, Wright FV. Addressing the challenges of collaborative goal setting with children and their families. Phys Occup Ther Pediatr 2014 May 15;34(2):138-152. [doi: 10.3109/01942638.2013.794187] [Medline: 23672252]

140. Jarvis JM, Gurga A, Greif A, Lim H, Anaby D, Teplicky R, et al. Usability of the Participation and Environment Measure Plus (PEM+) for client-centered and participation-focused care planning. Am J Occup Ther 2019 Jun 10;73(4):1-8. [doi: 10.5014/ajot.2019.032235] [Medline: $\underline{\text { 31318677] }}$

141. Jarvis JM, Kaelin VC, Anaby D, Teplicky R, Khetani MA. Electronic participation-focused care planning support for families: a pilot study. Dev Med Child Neurol 2020 Aug 07;62(8):954-961 [FREE Full text] [doi: 10.1111/dmcn.14535] [Medline: 32259292]

142. Khetani MA, Lim HK, Corden ME. Caregiver input to optimize the design of a pediatric care planning guide for rehabilitation: descriptive study. JMIR Rehabil Assist Technol 2017 Oct 24;4(2):e10. [doi: 10.2196/rehab.7566] 
143. Khetani MA, Cliff AB, Schelly C, Daunhauer L, Anaby D. Decisional support algorithm for collaborative care planning using the participation and environment measure for children and youth (PEM-CY): a mixed methods study. Phys Occup Ther Pediatr 2014 Mar 26;35(3):231-252. [doi: 10.3109/01942638.2014.899288] [Medline: 24670061]

144. Bennett CC, Hauser K. Artificial intelligence framework for simulating clinical decision-making: a Markov decision process approach. Artif Intell Med 2013 Jan;57(1):9-19. [doi: 10.1016/j.artmed.2012.12.003] [Medline: 23287490]

145. Lauritsen SM, Kristensen M, Olsen MV, Larsen MS, Lauritsen KM, Jørgensen MJ, et al. Explainable artificial intelligence model to predict acute critical illness from electronic health records. Nat Commun 2020 Jul 31;11(1):3852 [FREE Full text] [doi: 10.1038/s41467-020-17431-x] [Medline: 32737308]

146. Farzana S, Valizadeh M, Parde N. Modeling dialogue in conversational cognitive health screening interviews. In: Proceedings of the 12th International Conference on Language Resources and Evaluation (LREC 2020). 2020 Presented at: 12th International Conference on Language Resources and Evaluation (LREC 2020); May 13-15, 2020; Marseille, France p. 1167-1177 URL: https://tinyurl.com/mdpeccs5

147. Farzana S, Parde N. Exploring MMSE score prediction using verbal and non-verbal cues. In: Procedings of the Interspeech 2020 Conference. 2020 Presented at: Interspeech 2020 Conference; Oct 25-29, 2020; Shanghai, China p. 2207-2211. [doi: 10.21437/Interspeech.2020-3085]

148. Di Palo F, Parde N. Enriching neural models with targeted features for dementia detection. In: Proceedings of the 57th Annual Meeting of the Association for Computational Linguistics: Student Research Workshop. 2019 Presented at: 57th Annual Meeting of the Association for Computational Linguistics: Student Research Workshop; Jul 2019; Florence, Italy p. 1-7. [doi: $10.18653 / \mathrm{v} 1 / \mathrm{p} 19-2042]$

149. Bosak DL, Jarvis JM, Khetani MA. Caregiver creation of participation-focused care plans using Participation and Environment Measure Plus (PEM+), an electronic health tool for family-centred care. Child Care Health Dev 2019 Nov 30;45(6):791-798. [doi: 10.1111/cch.12709] [Medline: 31313843]

150. Arakelyan S, Maciver D, Rush R, O'hare A, Forsyth K. Family factors associated with participation of children with disabilities: a systematic review. Dev Med Child Neurol 2019 May 06;61(5):514-522 [FREE Full text] [doi: 10.1111/dmcn.14133] [Medline: 30613957]

151. Bult MK, Verschuren O, Jongmans MJ, Lindeman E, Ketelaar M. What influences participation in leisure activities of children and youth with physical disabilities? A systematic review. Res Dev Disabil 2011 Sep;32(5):1521-1529. [doi: 10.1016/j.ridd.2011.01.045] [Medline: 21388783]

152. Shikako-Thomas K, Majnemer A, Law M, Lach L. Determinants of participation in leisure activities in children and youth with cerebral palsy: systematic review. Phys Occup Ther Pediatr 2008 May 10;28(2):155-169. [doi: 10.1080/01942630802031834] [Medline: 18846895]

153. More than numbers: a guide toward diversity, equity and inclusion (DEI) in data collection. Charles and Lynn Schusterman Family Foundation. 2020. URL: https://philanthropynewyork.org/resources/ more-numbers-guide-toward-diversity-equity-and-inclusion-dei-data-collection-charles-and [accessed 2021-09-20]

154. Imms C, Adair B, Keen D, Ullenhag A, Rosenbaum P, Granlund M. 'Participation': a systematic review of language, definitions, and constructs used in intervention research with children with disabilities. Dev Med Child Neurol 2016 Jan 28;58(1):29-38 [FREE Full text] [doi: 10.1111/dmcn.12932] [Medline: 26411643]

\section{Abbreviations \\ AI: artificial intelligence \\ ASD: autism spectrum disorder \\ HMI: human-machine interaction \\ ML: machine learning \\ NLP: natural language processing \\ VR: virtual reality}

Edited by G Eysenbach; submitted 13.11.20; peer-reviewed by AV Das, P Tripathi, C Yu, M Majurul Ahsan; comments to author
$27.01 .21 ;$ revised version received 21.05.21; accepted 07.09.21; published 04.11.21
Please cite as:
Kaelin VC, Valizadeh M, Salgado Z, Parde N, Khetani MA
Artificial Intelligence in Rehabilitation Targeting the Participation of Children and Youth With Disabilities: Scoping Review
J Med Internet Res $2021 ; 23(11):$ e25745
URL: $\underline{\text { https://www.jmir.org/2021/11/e25745 }}$
doi: $10.2196 / 25745$
PMID:


(C) Vera C Kaelin, Mina Valizadeh, Zurisadai Salgado, Natalie Parde, Mary A Khetani. Originally published in the Journal of Medical Internet Research (https://www.jmir.org), 04.11.2021. This is an open-access article distributed under the terms of the Creative Commons Attribution License (https://creativecommons.org/licenses/by/4.0/), which permits unrestricted use, distribution, and reproduction in any medium, provided the original work, first published in the Journal of Medical Internet Research, is properly cited. The complete bibliographic information, a link to the original publication on https://www.jmir.org/, as well as this copyright and license information must be included. 